Анастасов А.Г., Щербинин А.В., Зубрилова Е.Г.

гОО ВПО ДОННМУ ИМ.М.ГОРЬКОГО

Республиканская детская клиническая больница МЗ ДНР, Донецк, ДНР

\title{
ВНУТРИБРЮШНОЕ КРОВОТЕЧЕНИЕ/ШОК И ОСОБЕННОСТИ ГОМЕОСТАЗА У ДЕТЕЙ С ИЗОЛИРОВАННОЙ ТУПОЙ ТРАВМОЙ ЖИВОТА, РАЗРЫВОМ СЕЛЕЗЕНКИ
}

\section{ВСТУПЛЕНИЕ}

Качество диагностики и правильный выбор лечения детей с тупой изолированной травмой селезенки остается одной из актуальных проблем практической медицины и связано с функциями селезенки как органа в системе гомеостаза. Травма селезенки занимает первое место и составляет от $48 \%$ до $77 \%$ у детей. По данным компьютерной томографии у более 80\% детей типичны необширные повреждения до 30\% поверхности селезенки. Обширные повреждения с площадью $50 \%$ и более встречаются только у 2,4\% детей. Существенное значение в правильном выборе тактики лечения пострадавшего ребенка играет корректная оценка тяжести поражения с использованием разноплановых формализованных балльных оценочных систем. Мировое общество неотложных хирургов (World Society of Emergency Surgary: WSES) предложило классификацию повреждений селезенки в соответствии с классификацией AAST и гемодинамическим статусом пациента. При отсутствии возможности проведения компьютерной томографии, эхография в диагностике закрытых повреждений селезенки имеет высокую информативность, но разрешающая способность метода во многом определяется фактически временем, прошедшим с момента травмы. По данным некоторых авторов, наиболее точным предиктором выбора метода лечения травмы селезенки является объем гемоперитонеума, который ассоциируется с тяжестью кровопотери и гемодинамическим статусом пациента.

Интенсивная терапия и переход к оперативной тактики лечения базируется на клинических рекомендациях «Травма органов брюшной полости у детей (S 36): S 36.0 - Травма селезенки у детей», Утверждены Российской ассоциацией детских хирургов, согласованы Научным советом Министерства Здравоохранения 35

Анастасов А.Г. и соавт.
Российской Федерации, 2019. Валидность клинических показателей прогноза тяжести гиповолемического состояния в остром периоде травмы относится к категории доказательности С. По данным Сафарова З.Ф., с соавторами (2019) возникает необходимость разработки диагностических критериев с высокой степенью чувствительности и специфичности для оценки выраженности шока.

Таким, образом ретроспективное определение валидных показателей оценки степени выраженности кровопотери при комбинированном лечении у детей с изолированной травмой селезенки является актуальным.

ЦЕЛЬ ИССЛЕДОВАНИЯ

Определение особенностей клиники внутрибрюшного кровотечения/шока у детей с изолированной травмой, разрывом селезенки, подвергшимся окончательной остановки кровотечения путем спленэктомии.

\section{МАТЕРИАЛ И МЕТОДЫ}

Ретроспективный клинический анализ изменений гомеостаза был проведен у 28 пациентов, возрастом от 6 до 12 лет $(9,5 \pm 0,77$ лет), с массой тела 28,4凶6,5 кг, находящиеся на лечении с изолированной тупой травмой селезенки, у которых в связи с неэффективностью консервативной терапии прибегали к оперативному вмешательству (спленэктомия) в Клинике детской хирургии им. Н.Л. Куща на базе Республиканской детской клинической больницы г. Донецка с 2016 г. по 2021 г.

Оценка тяжести и прогноз механической травмы проводились на основании педиатрической шкалы тяжести травмы (Pediatric Trauma Score (PTS) (Tepas J.J.,1985)), модифицированной шкалы тяжести травмы - Revised Trauma score (RTS) (Fitzmaurice L.S. 1997). Диагностика и хирургическое лечение при механической травме селезенки проводилась на 
основании Клинических рекомендаций «Травма органов брюшной полости у детей (S 36): S 36.0 - Травма селезенки у детей, разработанные Российской ассоциацией детских хирургов, Российским обществом хирургов, МЗ РФ, 2019 г.

С момента поступления в стационар, у всех больных проводилась количественная оценка боли, используя визуально - аналоговую шкалу (ВАШ). Также, пациентам основной группы проводилась профилактическая антибактериальная терапия препаратами в дозировках, рекомендованные инструкциями по применению этих лекарственных средств.

Инфузионная терапия у основной группы пациентов заключалась во внутривенном введении солевых растворов (0,9 \% раствор NaCL, раствор Рингера) 40 мл/ кг и при необходимости эритроцитарной массы на основании протокола жизнеобеспечения Комитета травмы Американской коллегии хирургов (ATLS).

Анестезиологический риск у пациентов II подгруппы по шкале ASA (American Society of Anesthesiologists - Американская ассоциация анестезиологов) соответствовал III степени. Премедикация у этих пациентов предусматривала внутривенное введение раствора атропина в дозе 0,05 мг/кг и раствора димедрола в дозе 0,05 мг/кг. Анестезиологическое пособие проводили путем комбинированного общего обезболивания с ИВЛ. Всем пациентам основной группы выполнялось комбинированное анестезиологическое пособие с внутривенным введением 5\% раствора кетамина 3,0®0,8 мг/ кг/час и 0,005 \% раствора фентанила 0,01 мг/кг/час. Миорелаксация достигалась болюсным введением антидеполяризующего миорелаксанта рокурония бромида в дозе 0,6 мг/кг. Средняя доза его на операцию составила 0,01区 0,004мг/кг/ час. Всем больным во время нахождения в отделении интенсивной терапии также проводилась респираторная поддержка. Выбор метода респираторной поддержки у больных основывался на тяжести нарушений газообменной функции легких и наличия дисфункции со стороны других органов и систем организма пациента.
На этапах анестезиологического обеспечения и оперативного вмешательства осуществляли динамический мониторинг (монитор пациента "Neptune") показателей ИВЛ: дыхательный объем, минутный объем вентиляции (МOB), частота аппаратного дыхания, а также контролировали содержание СО2 в конце выдоха (PetCO2), насыщение крови кислородом (SpO2) и АД сист.

Ведущее место в арсенале обезболивающих средств в послеоперационном периоде у больных обеих групп, занимали опиоидные аналгетики (0,005 \% раствор фентанила в дозе 1 мкг/кг/час или 1\% раствор промедола в дозе 0,5 мг/кг - 3 раза в сутки) с использованием парентерального болюсного и инфузионного пути введения. Количественный и качественный состав инфузионной терапии в послеоперационном периоде у пациентов определяли на основании характера текущих патологических потерь, физиологической суточной потребности пациента в жидкости.

Лабораторные исследования у пациентов предусматривали изучение показателей клинических и биохимических анализов крови. Определяли показатели клинического анализа крови: гемоглобин (колориметрический метод Сали), гематокрит (расчет по среднему объему эритроцита и числу эритроцитов), количество эритроцитов и лейкоцитов (гемоцитометрический метод Горяева), показатели лейкограммы. А также изучали биохимические анализы: уровень мочевины, глюкозы крови. Забор венозной крови у пациентов основной группы в течение первых 6 часов с момента поступления в стационар (1-й этап исследования) и к концу 3 суток после операции (2-ой этап исследования).

Результаты и обсуждение. Средняя длительность хирургического вмешательства (спленэктомия) у пациентов

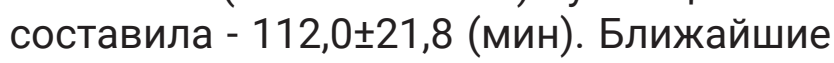
результаты хирургического и интенсивного лечения, т.е. исход заболевания у обследованных пациентов благоприятный, летальность отсутствовала, послеоперационных абдоминальных осложнений у 
у пациентов не зарегистрировано.

В предоперационном периоде, у всех больных с повреждением паренхимы селезенки, абдоминальный болевой синдром оценен 4,5®1,1 баллов. У пациентов наблюдалась нормотермия, $\mathrm{t}$ тела

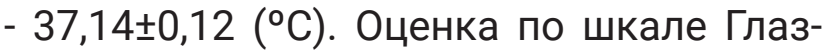
го составила $11,3 \otimes 1,2$ баллов. ЧД у пациентов составляла 29,5凶1,12 (дыханий в мин). Сердечная деятельность была ритмичная с чСС 90,23 $\pm 4,23$ (уд. в мин). Проба наполнения капилляров - 1,5区0,13 (сек), АД сист. - 85,35 $\pm 3,04$ (мм рт.ст.), Sp02 - 91,2ष1,1 (\%). Скорость диуреза $1,0 \otimes 0,2$ (мл/кг/час).

В первые 6 часов с момента госпитализации в стационар, у детей выраженность кровопотери и шока соответствовала I классу (снижение ОЦК <15\%) по шкале ATLS при повреждении селезенки 2-3 степени. Суммарная оценка тяжести травмы по шкале PTS была 10,2®1,1 балла, RTS 10,7凶0,6 балла, т.е. «легкая травма», в связи с повреждений одного органа одной анатомической области, без скелетной травмы. Основными статистически значимыми показателями были АД сист. и объем гемоперитонеума по данным УЗИ - 332,5 8,90 (мл) при нормальном значении индекса шока - 1,06 0,4.

В периоперационном периоде у пациентов зарегистрирован умеренный лейкоцитоз, уровень глюкозы крови соответствовал верхней границе нормы, имели место изменения показателей гемограммы (уровень, гемоглобина, гематокрита, количества тромбоцитов), что свидетельствовало о постгеморрагической анемии. По всей видимости, тенденцию снижения общего количества тромбоцитов обосновывали потреблением тромбоцитов в формировании первичного сгустка (формирование гематомы) в поврежденной ткани селезенки, т.е. активацией тромбоцитарного звена свертывающей системы крови. Ускорение СОЭ с низким лейкоцитозом у данного контингента пациентов как проявление системной воспалительной реакции на повреждение.

К 3 суткам стационарного лечения у пациентов статистических значимых отличий по изучаемым клинико-лаборатор- ным показателям от предыдущего (1-й этап) исследования не зарегистрировано, за исключением регресса выраженности болевого синдрома. На 2-ом этапе исследования не были статистически значимыми различия показателей периферической гемодинамики, в связи с проведенной окончательной остановкой паренхиматозного кровотечения, но сохранялись гемореологические изменения у пациентов в виде более низкого

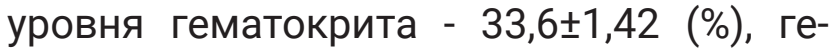
моглобина - 94,13 3,87 (г/л), тромбоцитов - 179,44 $\pm 22,16$ (×109/ л).

Таким, образом в первые 6 часов смомента поступления в стационар у пациентов с изолированной тупой травмой, разрывом паренхимы селезенки тяжесть нарушений гомеостаза чаще соответствовала среднему/тяжелому состоянию, характеризующему умеренном выраженным абдоминальным болевым синдромом, 1 классом кровопотери (<15\%ОЦК) с соответственной артериальной гипотензией, снижением показателей гемограммы, которые и выступали унифицированными критериями в оценке тяжести травмы и выборе дальнейшего оперативного лечения.

Выводы. Выраженность синдрома кровотечения/шока у детей с изолированной тупой травмой с разрывом селезенки определяется классом повреждения селезенки по AAST, а также объемом гемоперитонеума по данным УЗИ.

Основными диагностическими критериями органной дисфункции у детей с тупой травмой живота и разрывом селезенки выступали показатели, характеризующие степень расстройств периферического кровообращения (АД сист.), а индекс шока, оценочные шкалы: педиатрическая шкала тяжести травмы, модифицированная шкала тяжести травмы были малоинформативными.

Ведущим патологическим синдромом в течение раннего послеоперационного периода у детей с тупой изолированной травмой селезенки выступала лабораторно подтвержденная постгеморрагическая анемия II степени, которая не требовала гемотрансфузии. 
Сведения об авторах

Анастасов А.Г. д.мед.н., доцент кафедры детской хирургии и анестезиологии ГОО ВПО «Донецкий национальный медицинский университет им.М.Горького». Адрес: пр. Ильича, 16, г. Донецк, 83003.

Щербинин А.В. - к.мед.н., доцент, заведующий кафедрой детской хирургии и анестезиологии ГОО ВПО «Донецкий национальный медицинский университет им.М.Горького». Адрес: пр. Ильича, 16, г. Донецк, 83003.

Зубрилова Е.Г. врач-анестезиолог ГБУ РДКБ 